\title{
Effect of Anti-stress Activity of Fluoxetine on Restrained Stress Induced Male Albino Rats in Hematological Parameters and Whole Brain Histopathology
}

\author{
Rohini S. Kori ${ }^{1}$, Ravindranath H. Aladkatti ${ }^{2}$, S.D.Desai ${ }^{3}$, Kusal K.Das ${ }^{4 *}$ \\ 'Department of Anatomy, Shri B.M.Patil Medical College, Hospital and Research Centre, BLDE University, Vijayapura-586103, Karnataka, INDIA. \\ ${ }^{2}$ Central Animal Facility, Indian Institute of Science, Bengaluru-560012, Karnataka, INDIA. \\ 3Department of Anatomy, Sridevi Institute of Medical Science, Tumkur, Karnataka, INDIA. \\ ${ }^{4}$ Laboratory of Vascular Physiology \& Medicine, Department of Physiology, Shri B.M.Patil Medical College, Hospital and Research Centre, BLDE University, Vijaya- \\ pur-586103, Karnataka, INDIA.
}

\begin{abstract}
Objective: In this study we investigated the effect of Fluoxetine, a selective serotonin reuptake inhibitor, on the gravimetry, hematology and whole brain histopathology in the restrained stressed male albino rats. Methodology: Adult male Wistar albino rats weighing about $175-225 \mathrm{~g}$ were taken for the study and were divided into four groups of six animals each. Group I (control), Group II (stress induced), Group III (stress + withdrawal) and Group IV (stress + Fluoxetine, $20 \mathrm{mg} / \mathrm{kg}$ body weight, i.p.). The gravimetrical parameters, hematological parameters and whole brain histopathology of all the experimental rats were evaluated. Results: After 42 days of restraint stress, there was a significant $(P \leq 0.05)$ decrease final body weight, whole brain weight, $\mathrm{Hb}, \mathrm{RBC}, \mathrm{MCV}, \mathrm{MCH}$, total $\mathrm{WBC}$ and Platelets, whereas increase in Neutrophils, lymphocytes, eosinophils and monocytes in Group II of restraint stress rats when compared with their control group I. The stress withdrawal group (Group III) and drug Fluoxetine treatment (Group IV) shown significantly $(P \leq 0.05)$ improvement in gravimetry, hematological parameters and whole brain histopathology in restraint stress compared to only stress induced group II. Conclusion: The drug
\end{abstract}

Fluoxetine treatment could exert a protective effect on restrained stress induced alterations in gravimetrical parameters, hematological parameters and whole brain histopathology of male albino rats.

Key words: Brain, Fluoxetine, Gravimetry, Hematology, Histopathology, Stress.

Correspondence :

Prof. Kusal K. Das,

Professor, Department of Physiology,

Shri B.M.Patil Medical College, Hospital and Research Centre, BLDE University, Vijayapur-586103.Karnataka state, INDIA.

Phone no: +91-9448194257

Email: kusaldas@yahoo.com

DOI: 10.5530/jyp.2017.9.48

\section{INTRODUCTION}

Stress is constant in our lives and cannot be avoided. Stress can be viewed as a cause of adverse circumstances that induces a wide range of biochemical and behavioral changes. ${ }^{1,2}$ Effects of stress on different organs of the body have been extensively investigated in both humans and experimental animals and study revealed that severe stress lasting weeks or months can impair cell communication in the brain's region. ${ }^{3}$ Adverse life events occurring in early development can result in long term effects on organs development and may lead to abnormal conditions. Oxidative damage is an established outcome of stress that has been implicated in the pathogenesis of mood and anxiety disorders. ${ }^{4}$

Anti-stress drugs are widely used for the treatment of stress. Selective serotonin reuptake inhibitors (SSRIs) are the major and dominant class of antidepressants used over the last decade whereas ancient groups of most widely used antidepressants were Tricyclic antidepressants (TCA) and monoamine oxidase inhibitors. Fluoxetine, a selective serotonin reuptake inhibitor, is a first-line antidepressant drug, effectively treats a stress disorders ${ }^{5}$ and protects from the harmful effects of various types of stressors. ${ }^{6,7}$ It also attenuates effects of stress on hematological parameters ${ }^{8}$ and prevent from oxidative damage. ${ }^{9}$ Fluoxetine has emerged as the treatment of choice for depression because of its safer profile, fewer side effects and improved tolerability compared with the older tricyclic antidepressants. ${ }^{10}$ However, the underlying mechanisms of its therapeutic efficacy remain unclear. Hence, the aim of this study was to evaluate the effect of drug Fluoxetine on restrained stress on gravimetrical parameters, hematological parameters and whole brain histopathology in male albino rats.

\section{MATERIAL AND METHODS}

Animals and Ethics

Colony bred healthy adult male albino rats (Wistar strain) weighing 175-225 g was utilized from Central Animal Facility, Indian Institute of Science, Bengaluru for the experiments. Wister rats fed with laboratory stock diet (Hindustan lever, Mumbai, India) and water ad libitum. They acclimatized a week to the laboratory conditions at $22-24^{\circ} \mathrm{C}$ and a $12 \mathrm{~h}$ light: dark (circadian) cycle. All the animals were sacrificed at the end of the last dose after an overnight fast. All the experimental procedures followed were performed in accordance with the approval of the Institutional Animal Ethics Committee (IAEC/477/2016) under strict compliance of Committee for the Purpose of Control and Supervision of Experiments on Animals (CPCSEA) guidelines for the experimental studies. 


\section{Study Groups}

The acclimatized animals divided into four groups of six animals each and three animals were kept in each metabolic wire cage $(60 \times 30 \times 20 \mathrm{~cm})$. Group I (untreated control) rats were healthy controls, kept undisturbed in the home cage throughout the experimental period for 42 days. Group II (stress induced) rats were stressed in a wire mesh restrainer for 6 hrs/day for 42 days. ${ }^{11}$ Group III (stress withdrawal) rats were stressed for 21 days and withdrawal of stress for remaining 21 days and Group IV (stress + Fluoxetine) rats were stressed for 21 days and treated with drug Fluoxetine $\left(20 \mathrm{mg} / \mathrm{kg}\right.$ body weight, i.p.). ${ }^{12}$

\section{Stress Procedure}

Rats were subjected to restrained stress in a wire mesh restrainer for 6 hours per day for 21 days. The wire mesh restrainer had a wooden base and stainless steel wire mesh restrainer hinged to the base. The restrainer having the dimensions of $8 \mathrm{~cm}(\mathrm{~L}) \times 4 \mathrm{~cm}(\mathrm{~B}) \times 4 \mathrm{~cm}(\mathrm{H})$ was used for the experiments. A pad lock and latch helped to secure the rat in the restrainer. ${ }^{11}$

\section{Gravimetry}

The body weight of all the rats was recorded on the day 1 of treatment, alternate $10^{\text {th }}$ day and the day of sacrifice (i.e. $42^{\text {nd }}$ day). Percent body weight gain was determined in experimental groups of the rats with a ratio of final body weight to the initial body weight. Organ somatic index was determined by the ratio of organ weight to body weight of rat before sacrifice (final body weight).

\section{Hematological parameters}

The blood collected from retro orbital method. Blood was collected in centrifuge tubes, kept at room temperature for about $2 \mathrm{~h}$ and centrifuged at $1500 \times g$ for $15 \mathrm{~min}$ to collect serum. Hematological parameters such as PCV, Hb, RBC, MCV, MCHC, MCH, TWBC, Platelets, Neutrophils, Lymphocytes, Eosinophils and Monocytes were analyzed by using SYS MAX-35 automated cell counter machine.

\section{Whole brain histopathological evaluations}

The whole brain of the experimental rats were dissected out and subjected to histopathological evaluations. ${ }^{13}$ The microscopic study on routine stain (Hematoxylin and Eosin stain) were done and the following changes of the tissues of control and various treated groups were observed; viz. atrophy, degeneration, necrosis, inflammation, tumorogenecity etc. Photomicrographs were taken out with the help of PC connected MIPS (Magnifying Image Processing System).

\section{Statistical analysis}

Data were expressed as mean \pm standard deviation of the mean. Statistical comparisons were performed by one-way ANOVA, followed by posthoc t-test and $\mathrm{P} \leq 0.05$ is considered to indicate a significant difference between experimental and controls.

\section{RESULTS AND DISCUSSION}

\section{Gravimetry}

Our observations indicate no adverse reactions were observed in any of the experimental groups and remained active and healthy with normal feeding behavior. However, restrained stress (chronic moderate stress) adversely affects on body weight of rats (Table 1). Stress induced rats (Group II) were found to be lethargic and their body weights decreased remarkably which is indicated by the mean percentage of body weight gain of $14.07 \%$, as compared to their mean initial body weight gain (25.06\%). Group IV (stress + Fluoxetine) rats exhibited no significant change in mean percentage of body weight gain (23.86\%) from the mean initial percentage of body weight gain. However, Group III (stress withdrawal) rats had a non-significant increase in mean initial percentage of body weight gain $(26.35 \%)$ as compared to untreated controls. Table 1 also illustrated that stress induced (Group II) rats had a significant decrease in whole brain weight and organ somatic index as compared to controls (Group I), excluding Fluoxetine treated (Group IV) showed a significant increase weight and organ somatic index. Whereas Group III, exhibited no change in whole brain weight and organ somatic index compared to controls. The adverse affects on body weight of rats may be due to low food consumption, hormonal imbalance and protein metabolism. Evidences shown the decrease in body weight could be due to the direct effect of stress on the food intake behavior of the rats ${ }^{14}$ and stress might have increased the protein catabolism and hampered the utilization of food consumed during the stress period, thereby causing decrease in body weight. ${ }^{15}$ The treatment with drug Fluoxetine had cut down the percentage decrease in body weight of group IV rats.

\section{Hematological parameters}

Stress induced changes in hematological parameters clearly showed anemia, and it may be due to release of immature RBCs in circulation. However, in our study, the decrease in hemoglobin concentration, RBC count, total WBC count and MCV may be due to non-regenerative anemia arising from stress induced disorder of hematopoietic stem cells resulting in decreased erythrocyte, leukocyte and platelet count. The treatment of Fluoxetine decreased the stress induced effect on hematological values and also showed a protective role in anemia and leucopenia (Table 2).

A protective effect of Fluoxetine on leucocytes from oxidative stress was observed and results revealed that exposure to restraint stress induced peripheral oxidative stress, which is defined by an increase in the generation of reactive oxygen species (ROS) in peripheral blood lymphocytes, granulocytes and monocytes. These adverse effects were partially reversed by Fluoxetine indicating that it is capable of alleviating oxidative damage induced by psychological stress on the peripheral immune system. Our findings are in agreement with other studies showing that the production of ROS by immune cells might be influenced by psychological stress. However, the available results in reference to the influence of psychological stress on the production of ROS are contradictory, ${ }^{16,17}$ while others have shown a decreased ROS production. ${ }^{18,19}$ This discrepancy may have been the result of a number of research design problems, including age, sex, intensity and type of stressor, plasma concentration of catecholamine and lack of adequate non-stressed controls, which are very important since a circadian rhythm in the generation of these compounds has been described. ${ }^{20}$

Many of effects mediated by stress-induced neurochemical and hormonal abnormalities that are often associated with oxidative stress. ${ }^{21,22}$ Three main pathways of ROS generation in the course of depression have been described: (i) deficiency of monoamines or increased metabolism of monoamines; (ii) increased glutaminergic transmission; and (iii) activation of immune and inflammatory response systems. ${ }^{23}$ Taking into account the available evidence, we believe that the potentially favorable antioxidant effect of the Fluoxetine could be mediated by above mentioned mechanisms. It has been noted that Fluoxetine restores not only normal metabolism of monoamines but also their physiological levels in synaptic clefts. Considering the ROS-scavenging potential of monoamines, this effect of Fluoxetine imposes a limitation on free radical reactions and concentration of their products. ${ }^{24}$ Increased glutaminergic transmission is characteristic of depression. ${ }^{25}$ High levels of glutamate, in terms of pathological, can cause excitotoxicity by allowing high levels of calcium ions to enter the cell, which, if present in excess, stimulate the production 
of ROS. Fluoxetine has a cytoprotective effect involving limitation of overproduction of calcium ions. ${ }^{26}$ Fluoxetine is capable of reducing the immune and inflammatory components ${ }^{27,28}$ that favor the generation of ROS. $^{23}$

This antidepressant drug has been shown to inhibit the expression of pro-inflammatory cytokines ${ }^{27}$ and prostaglandin E2 ${ }^{28}$ that are involved in enhancing ROS. ${ }^{23}$ Its inhibitory effects have been suggested to be mediated, in part, by the protein kinase A..$^{27}$ Our present data show that Fluoxetine is effective to counteract the adverse effects of stress. Stressed rats might be more predisposed to diseases such as infections and chronic inflammation than non-stressed rats, as the oxidative stress is present in their peripheral defense cells. As treatment with Fluoxetine ameliorates stress-induced oxidative damage, this study demonstrates that improvement in cellular oxidative status may be an important mechanism underlying the protective pharmacological effects of Fluoxetine, which are clinically observed in the treatment of depressive disorders.

\section{Whole brain histopathological evaluations}

Stress is a pathogenic factor and contributes to the progression of neuroinflammation and neuronal death. The whole brain histological observations illustrated whole brain section of normal cerebral cortex (Figure 1) consisting of neuronal cells possessing round central placed nuclei in moderate amphophilic cytoplasm and embedded in fibrillar network and Figure 2 exhibited mild focal vacuolar degeneration in restrained stress rats. Stress stimuli, among other challenges emerging from the external and internal environment, alter circulating plasma composition. The central nervous system (CNS) is protected from these fluctuations by barriers, among which the blood-brain barrier (BBB) plays a key role in maintaining homeostasis. The BBB supplies the brain with oxygen, glucose, and other nutrients required for neural functions; it contributes to the optimal ionic and transmitter composition of the neural microenvironment for synaptic signaling, and protects the CNS against neurotoxic substances. ${ }^{29,30}$ Furthermore, our observations demonstrate that the whole brain histological observations modified in stress

Table 1: Effect of drug Fluoxetine on restrained stress induced alteration of gravimetry in male albino rats

\begin{tabular}{ccccc}
\hline Gravimetrical parameters & $\begin{array}{c}\text { Group I } \\
\text { (Untreated control) }\end{array}$ & $\begin{array}{c}\text { Group II } \\
\text { (Stress induced) }\end{array}$ & $\begin{array}{c}\text { Group III } \\
\text { (Stress Withdrawal) }\end{array}$ & $\begin{array}{c}\text { Group IV } \\
\text { (Stress + Fluoxetine,) }\end{array}$ \\
\hline Initial Body Weight (g) & $192.50 \pm 45.96^{\mathrm{a}}$ & $197.50 \pm 10.61^{\mathrm{a}}$ & $220.50 \pm 4.95^{\mathrm{a}}$ & $190.33 \pm 10.52^{\mathrm{a}}$ \\
10 Days after (g) & $203.00 \pm 46.67^{\mathrm{a}}$ & $198.00 \pm 7.07^{\mathrm{a}}$ & $238.00 \pm 9.90^{\mathrm{b}}$ & $200.83 \pm 12.95^{\mathrm{a}}$ \\
20 Days after (g) & $227.00 \pm 46.67^{\mathrm{a}}$ & $208.00 \pm 8.49^{\mathrm{a}}$ & $256.50 \pm 10.61^{\mathrm{b}}$ & $210.00 \pm 12.35^{\mathrm{a}}$ \\
30 Days after (g) & $231.50 \pm 44.55^{\mathrm{a}}$ & $218.50 \pm 12.02^{\mathrm{a}}$ & $262.50 \pm 7.78^{\mathrm{b}}$ & $224.00 \pm 10.51^{\mathrm{a}}$ \\
Final Body Weight (g) & $242.50 \pm 47.38^{\mathrm{a}}$ & $224.00 \pm 4.24^{\mathrm{b}}$ & $278.50 \pm 4.95^{\mathrm{c}}$ & $235.83 \pm 9.56^{\mathrm{a}}$ \\
Percentage Body Weight Gain (\%) & $25.06 \pm 5.51^{\mathrm{a}}$ & $14.07 \pm 3.27^{\mathrm{b}}$ & $26.35 \pm 2.98^{\mathrm{a}}$ & $23.86 \pm 1.95^{\mathrm{a}}$ \\
Brain weight (g) & $2.24 \pm 0.08^{\mathrm{a}}$ & $1.87 \pm 0.19^{\mathrm{b}}$ & $2.51 \pm 0.10^{\mathrm{a}}$ & $2.15 \pm 0.18^{\mathrm{a}}$ \\
Organ Somatic Index & $0.0092 \pm 0.03^{\mathrm{a}}$ & $0.0083 \pm 0.02^{\mathrm{b}}$ & $0.0090 \pm 0.01^{\mathrm{a}}$ & $0.0091 \pm 0.03^{\mathrm{a}}$ \\
\hline
\end{tabular}

Each value is Mean \pm SD of six observations in each group. In each row, values with different superscripts $(a, b, c)$ were significantly different from each other $(P<0.05)$. Post-hoc $t$-test analysis was used to test for differences among the means when ANOVA indicated a significant $P<0.05$.

Table 2: Effect of drug Fluoxetine on restrained stress induced alteration of haematological parameters in male albino rats

\begin{tabular}{|c|c|c|c|c|}
\hline Hematological parameters & $\begin{array}{c}\text { Group I } \\
\text { (Untreated control) }\end{array}$ & $\begin{array}{c}\text { Group II } \\
\text { (Stress induced) }\end{array}$ & $\begin{array}{c}\text { Group III } \\
\text { (Stress Withdrawal) }\end{array}$ & $\begin{array}{c}\text { Group IV } \\
\text { (Stress + Fluoxetine, ) }\end{array}$ \\
\hline PCV (\%) & $43.83 \pm 1.25^{\mathrm{a}}$ & $42.03 \pm 1.43^{\mathrm{a}}$ & $42.93 \pm 1.51^{\mathrm{a}}$ & $43.67 \pm 1.25^{\mathrm{a}}$ \\
\hline $\mathrm{Hb}(\mathrm{g} / \mathrm{dL})$ & $13.91 \pm 0.37^{\mathrm{a}}$ & $10.15 \pm 0.44^{\mathrm{b}}$ & $12.84 \pm 0.38^{\mathrm{a}}$ & $13.51 \pm 0.45^{\mathrm{a}}$ \\
\hline $\mathrm{RBC}\left(\mathrm{x} 10^{6} / \mu \mathrm{L}\right)$ & $7.48 \pm 0.35^{\mathrm{a}}$ & $5.77 \pm 0.34^{\mathrm{b}}$ & $7.10 \pm 0.37^{\mathrm{a}}$ & $8.30 \pm 0.35^{\mathrm{a}}$ \\
\hline $\mathrm{MCV}(\mathrm{FL})$ & $59.05 \pm 1.50^{\mathrm{a}}$ & $49.33 \pm 1.25^{\mathrm{b}}$ & $57.36 \pm 0.92^{\mathrm{a}}$ & $60.72 \pm 1.30^{\mathrm{a}}$ \\
\hline $\mathrm{MCHC}(\mathrm{g} / \mathrm{dL})$ & $34.51 \pm 1.21^{\mathrm{a}}$ & $39.58 \pm 0.92^{\mathrm{a}}$ & $35.11 \pm 1.35^{\mathrm{a}}$ & $34.58 \pm 1.14^{\mathrm{a}}$ \\
\hline $\mathrm{MCH}(\mathrm{pg})$ & $19.73 \pm 0.78^{\mathrm{a}}$ & $16.85 \pm 1.23^{\mathrm{b}}$ & $18.40 \pm 0.75^{\mathrm{a}}$ & $18.36 \pm 0.79^{a}$ \\
\hline Total WBC $\left(\times 10^{3} / \mu \mathrm{L}\right)$ & $11.30 \pm 0.62^{\mathrm{a}}$ & $9.70 \pm 0.83^{b}$ & $11.04 \pm 0.37^{\mathrm{a}}$ & $12.39 \pm 0.34^{a}$ \\
\hline Platelets (x $\left.10^{5} / \mu \mathrm{L}\right)$ & $1.12 \pm 0.05^{\mathrm{a}}$ & $0.85 \pm 0.08^{b}$ & $1.10 \pm 0.07^{\mathrm{a}}$ & $1.28 \pm 0.08^{\mathrm{a}}$ \\
\hline Neutrophils (\%) & $29.03 \pm 0.77^{a}$ & $39.50 \pm 0.79^{\mathrm{b}}$ & $31.20 \pm 1.23^{\mathrm{a}}$ & $30.16 \pm 0.97^{a}$ \\
\hline Lymphocytes (\%) & $79.13 \pm 7.44^{\mathrm{a}}$ & $105.7 \pm 7.80^{\mathrm{b}}$ & $93.88 \pm 5.51^{\mathrm{b}}$ & $76.09 \pm 6.67^{\mathrm{a}}$ \\
\hline Eosinophils (\%) & $2.20 \pm 0.30^{\mathrm{a}}$ & $3.60 \pm 0.24^{\mathrm{b}}$ & $2.58 \pm 0.17^{\mathrm{a}}$ & $2.03 \pm 0.20^{\mathrm{a}}$ \\
\hline Monocytes (\%) & $2.03 \pm 0.35^{\mathrm{a}}$ & $3.57 \pm 0.34^{\mathrm{b}}$ & $2.53 \pm 0.28^{\mathrm{a}}$ & $2.25 \pm 0.31^{\mathrm{a}}$ \\
\hline
\end{tabular}

Each value is Mean \pm SD of six observations in each group. In each row, values with different superscripts $(a, b, c)$ were significantly different from each other $(\mathrm{P}<0.05)$. Post-hoc t-test analysis was used to test for differences among the means when ANOVA indicated a significant $\mathrm{P}<0.05$. 

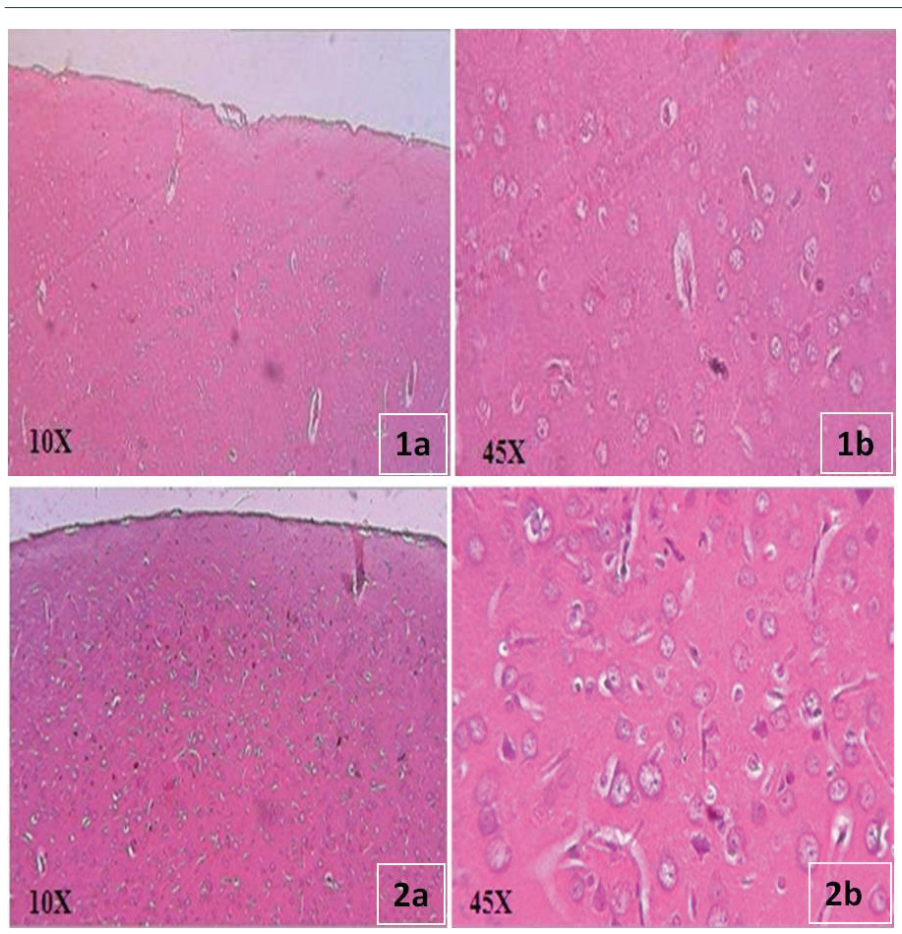

Figure 1a \& b: Whole brain section of normal control (Group I) and stress induced rats (Group II). Normal cerebral cortex with neuronal cells, round central placed nuclei and fibrillar network.

Figure 2a \& b: Cerebral cortex with neuronal cells, mild focal vacuolar degeneration and there were no features of necrosis, infarcts, inflammation or glial proliferation.

conditions. The impact of immobilization stress on the cellular and molecular components of the BBB is still unexplored (Figure 3). But after treatment of anti-stress drug Fluoxetine showed beneficial effect on brain degeneration (Figure 4). Our histopathological findings may help to explain the stress induced brain degeneration changes playing a role in the pathogenesis of several neurological and psychiatric diseases.

\section{CONCLUSION}

The exposure to restrained stress resulted in peripheral oxidative stress in male albino rats. Treatment with Fluoxetine has a significant effect to counteract restrained stress induced foregoing alterations. Fluoxetine may be an important mechanism underlying the protective pharmacological effects over restrained stress induced hematological and histopathological adverse change. Further, our particular interest to study the effect of Fluoxetine at the level of ultrastructural of cerebellum and understanding about the mechanism by which Fluoxetine exert its effect on the neuronal cells of cerebellar cortex which is one of the central regions in which ordered organizational patterns are most obvious.

\section{ACKNOWLEDGEMENT}

We deeply acknowledge BLDE University, Vijayapura for all the support pertaining to this work. Authors also acknowledge help, guidance and support of Dr. B.M. Bannur, Professor and Head of the Department of Anatomy, Shri B.M. Patil Medical College, Hospital and Research Center, Vijayapura.

\section{CONFLICTS OF INTEREST}

Authors declared there is no Conflict of interest.

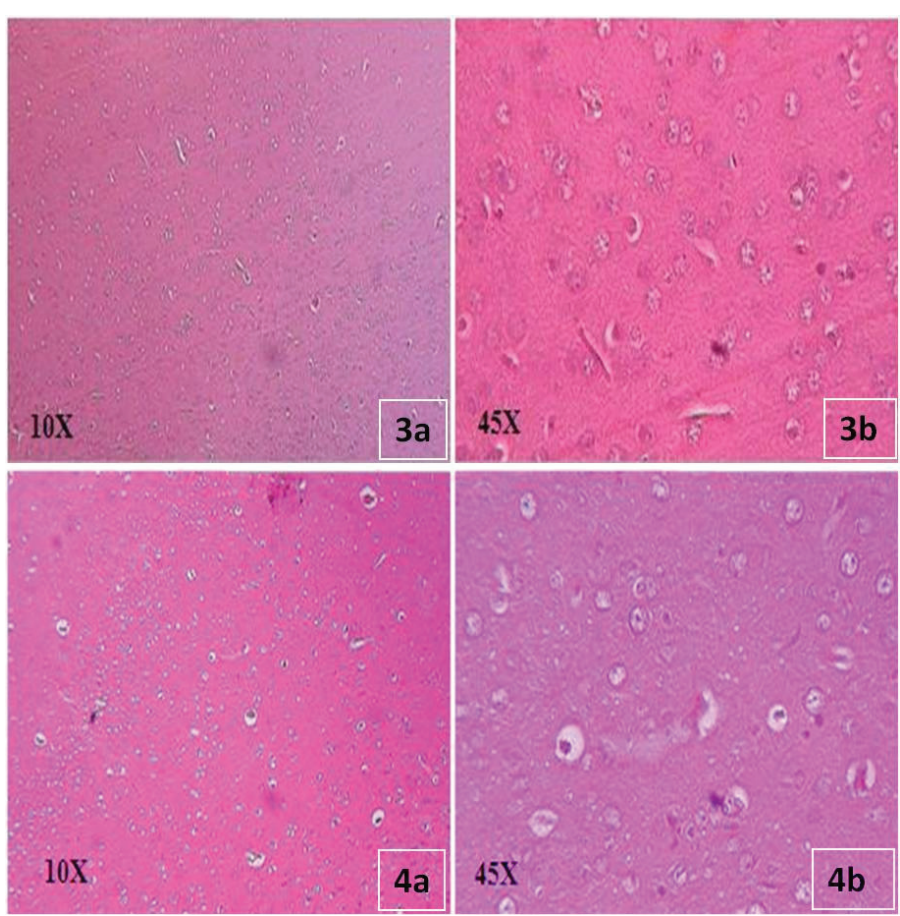

Figure 3a \& b: Whole brain section of stress withdrawal (Group III) and stress induced Fluoxetine treated rats (Group IV). Cerebral cortex with neuronal cells possessing round central placed nuclei in moderate amphophilic cytoplasm and embedded in fibrillar network.

Figure 4a \& b: Normal cerebral cortex with round central placed nuclei in moderate amphophilic cytoplasm and embedded in fibrillar network.

\section{ABBREVIATIONS USED}

ANOVA: Analysis of variance; CPCSEA: Committee for the purpose of Control and Supervision of Experiments on Animals; Hb: Hemoglobin; i.p: intra peritoneal; IAEC: Institutional Animal Ethics Committee; MCH: Mean Corpuscular Hemoglobin; MCHC: Mean Corpuscular Hemoglobin Concentration; MCV: Mean Corpuscular Volume; PCV: packed cell volume; RBC: Red Blood Cell; ROS: Reactive Oxygen Species; TWBC: total white blood cell count and WBC: White Blood Cells.

\section{REFERENCES}

1. Jaggi AS, Bhatia N, Kumar N, Singh N, Anand P, Dhawan R. A review on animal models for screening potential anti-stress agents. Neurol Sci. 2011;32(6): 993-1005.

2. Oxington KV. Psychology of Stress. New York, USA: Nova Science Publishers Inc 2005; 54-55

3. McEwen BS. Physiology and neurobiology of stress and adaptation: Central role of the brain. Physiol Rev. 2007; 87(3):873-904.

4. Bouayed J, Rammal H, Soulimani R. Oxidative stress and anxiety:Relationship and cellular pathways. Oxid Med Cell Longev. 2009;2(2):63-67.

5. Zohar J, Westenberg HG. Anxiety disorders: a review of tricyclic antidepressants and selective serotonin reuptake inhibitors. Acta Psychiatrica Scandinavica. 2000;101(S403):39-49.

6. Kindler S, Dolberg OT, Cohen H, Hirschmann S, Kotler M. The treatment of comorbid premature ejaculation and panic disorder with fluoxetine. Clin Neuropharmacol. 1997;20(5):466.

7. Vaswani M, Linda FK, Ramesh S. Role of selective serotonin reuptake inhibitors in psychiatric disorders: a comprehensive review. Prog Neuro-psychopharmacol Biol Psychiatry. 2003;27(1):85-102.

8. Núñez MJ, Balboa J, Rodrigo E, Brenlla J, González-Peteiro M, Freire-Garabal M. Effects of fluoxetine on cellular immune response in stressed mice. Neurosci Lett. 2006;396(3):247-51.

9. Zafir A, Ara A, Banu N. In vivo antioxidant status: a putative target of antidepressant action. Prog Neuropsychopharmacol Biol Psychiatry. 2009;33:220-8

10. Wilde MI, Benfield P. Fluoxetine. A pharmacoeconomic review of its use in 
depression. Pharmacoeconomics. 1998;13:543-61.

11. Kumar RS, Rao MS, Nayak S, Sareesh NN. Effect of Ocimum sanctum (Linn) extract on restraint stress induced behavioral defects in male wister rats. Pharmacologyonline. 2007;3:394-404.

12. Zafir A, Banu N. Antioxident potential of Fluoxetine in comparision to curcuma longa in restraint stressed rats. Eur J Pharmacol. 2007;572(1):23-31.

13. Culling CF, Ellison RT, Barr WT. Cellular Pathology Techniques. $4^{\text {th }}$ ed. London: Butterworth and Co.; 1985.

14. Wang S, Hu S, Zhang C, Qiu J, Li Y. Antidepressant-like activity of ChaihuShugan-San aqueous extract in rats and its possible mechanism. 2014;10:50-6.

15. First M, Gil-Ad I, Taler M, Tarasenko I, Novak N, Weizman A. The effects of fluoxetine treatment in a chronic mild stress rat model on depression-related behavior, brain neurotrophins and ERK expression. J Mol Neurosci. 2011;45(2):246-55.

16. Ng F, Berk M, Dean O, Bush Al. Oxidative stress in psychiatric disorders: evidence base and therapeutic implications. Int J Neuropsychopharmacol. 2008;11(6):851-76

17. Patki G, Solanki N, Atrooz F, Allam F, Salim S. Depression, anxiety-like behavior and memory impairment are associated with increased oxidative stress and inflammation in a rat model of social stress. Brain Research. 2013;1539:73-86.

18. Atanackovic D, Schulze J, Krcger H, Brunner-Weinzierl MC, Deter HC. Acute psychological stress induces a prolonged suppression of the production of reactive oxygen species by phagocytes. J Neuroimmunol. 2003;142:159-65.

19. McCarthy DO, Ouimet ME, Daun JM. The effects of noise stress on leukocyte function in rats. Res Nurs Health. 1992;15:131-7.

20. Atanackovic D, Brunner-Weinzierl MC, Krcger H, Serke S, Deter HC. Acute psychological stress simultaneously alters hormone levels, recruitment of lymphocyte subsets, and production of reactive oxygen species. Immunol
Invest. 2002;31:73-91.

21. Shaw PJ, Bergmann BM, Rechtschaffen A. Effects of paradoxical sleep deprivation on thermoregulation in the rat. Sleep. 1998;21:7-17.

22. Knutson KL, Spiegel K, Penev P, Van Cauter E. The metabolic consequences of sleep deprivation. Sleep Med Rev. 2007;11:163-78.

23. Galecki P, Szemraj J, Bien'kiewicz M, Florkowski A, Ga”lecka E. Lipid peroxidation and antioxidant protection in patients during acute depressive episodes and in remission after fluoxetine treatment. Pharmacol Rep. 2009;61:436-47.

24. Novío S, Núñez MJ, Amigo G, Freire-Garabal M. Effects of fluoxetine on the oxidative status of peripheral blood leucocytes of restraint-stressed mice. Basic Clin Pharmacol Toxicol. 2011;109(5):365-71.

25. Miller N, Schwarz MJ. The immune-mediated alteration of serotonin and glutamate: towards an integrated view of depression. Mol Psychiatry. 2007;12:988-1000.

26. LiYF, LiuYQ, Huang WC, Luo ZP. Cytoprotective effect is one of common action pathways for antidepressants. Acta Pharmacol Sin. 2003;24:996-1000.

27. Yaron I, Shirazi I, Judovich R, Levartovsky D, Caspi D, Yaron M. Fluoxetine and amitriptyline inhibit nitric oxide, prostaglandin E2, and hyaluronic acid production in human synovial cells and synovial tissue cultures. Arthritis Rheum. 1999; 42:2561-8.

28. Maes M. The immunoregulatory effects of antidepressants. Hum Psychopharmacol. 2001;16:95-103

29. Abbott NJ. Patabendige AA, Dolman DE, Yusof SR, Begley DJ. Structure and function of the blood-brain barrier. Neurobiol Dis. 2010;37:13-25.

30. Sántha P, Veszelka S, Hoyk Z, Mészáros M, Walter FR, Tóth AE, et al. Restraint Stress-Induced Morphological Changes at the Blood-Brain Barrier in Adult Rats. Front Mol Neurosci. 2016;8:88.

Article History: Submission Date: 17-10-16; Received Date: 19-11-16; Acceptance Date: 28-12-16 .

Cite this article: Kori RS, Aladkatti RH, Desai SD, Das KK. Effect of Anti-stress Activity of Fluoxetine on Restrained Stress Induced Male Albino Rats in Hematological Parameters and Whole Brain Histopathology. J Young Pharm. 2017;9(2):246-50. 